\title{
ANÁLISE DO ÍNDICE DE ARIDEZ DA BACIA HIDROGRÁFICA DO RIO PIRACURUCA - CEARÁ-PIAUÍ, NORDESTE DO BRASIL
}

\author{
Francílio de Amorim dos Santos ${ }^{1}$ \\ Lucia Maria Silveira Mendes ${ }^{2}$ \\ Maria Lúcia Brito da $\mathrm{Cruz}^{3}$
}

\begin{abstract}
Resumo: O estudo teve como objetivos realizar análise estatística e espacializar os dados da Precipitação Média Anual (P), Evapotranspiração Potencial (ETP) e Índice de Aridez (Ia) na Bacia hidrográfica do rio Piracuruca (PI-CE), como forma de conhecer as áreas com maior rigor climático e subsidiar ações de planejamento ambiental. Os dados do Sistema de Informações Hidrológicas (HidroWEB), da Agência Nacional de Águas (ANA), permitiram apontar que: a) os maiores totais pluviométricos se concentram na parte leste da bacia, sob influência da altitude do Planalto da Ibiapaba; b) os maiores níveis de ETP concentram-se no setor Centro-Oeste da bacia, onde ocorrem as temperaturas médias anuais mais elevadas; c) os mais altos níveis de Ia concentram-se também no setor Centro-Oeste, trecho referente às áreas aplainadas piauiense que apresentam os menores totais de precipitação e os maiores valores de ETP. Esses dados devem subsidiar estudos posteriores e permitir a elaboração e implantação de adequado planejamento ambiental.
\end{abstract}

Palavras-chave: Precipitação; Evapotranspiração Potencial; Rigor Climático; Bacia de Drenagem.

\section{ANALYSIS OF THE ARIDITY INDEX OF THE HYDROGRAPHIC BASIN OF PIRACURUCA RIVER, NORTHEAST OF BRAZIL}

Abstract: The objective of the study was to perform a statistical analysis and to characterize the Annual Average Precipitation (P), Potential Evapotranspiration (ETP) and Aridity Index (Ia) data in the Piracuruca River basin (PI-CE), as a way to know the areas with greater climatic rigor and subsidize environmental planning actions. Data from the Hydrological Information System (HidroWEB) of the National Water Agency (ANA) showed that: a) the highest rainfall totals are concentrated in the eastern part of the basin, influenced by the altitude of the Ibiapaba Plateau; b) the highest levels of ETP are concentrated in the CentralWest sector of the basin, where the highest average annual temperatures occur; c) the highest levels of Ia are also concentrated in the Central-West sector, a section referring to the flattened areas of Piauí which present the lowest total precipitation and the highest values of ETP. These data should support subsequent studies and allow the development and implementation of adequate environmental planning.

Keywords: Precipitation; Potential Evapotranspiration; Climate Rigor; Drainage Basin.

\footnotetext{
${ }^{1}$ Doutorando em Geografia (UECE). Docente do Instituto Federal do Piauí / Campus Piripiri. E-mail: francilio.amorim@ifpi.edu.br.

${ }^{2}$ Doutora em Agronomia. Laboratório de Geoprocessamento e Estudos Aplicados (LabGeo), da Universidade Estadual do Ceará / Campus do Itaperi. E-mail: lucia.mendes@uece.br.

${ }^{3}$ Doutora em Geografia. Laboratório de Geoprocessamento e Estudos Aplicados (LabGeo), da Universidade Estadual do Ceará / Campus do Itaperi. E-mail: mlbcruz@gmail.com.
} 


\section{ANÁLISIS DEL ÍNDICE DE ARIDEZ DE LA CUENCA HIDROGRÁFICA DEL RÍO PIRACURUCA, NORDESTE DEL BRASIL}

Resumen: El estudio tuvo como objetivos realizar análisis estadísticos y espacializar los datos de la Precipitación Media Anual (P), Evapotranspiración Potencial (ETP) e Índice de Aridez (Ia) en la cuenca del río Piracuruca (PI-CE), como forma de conocer las áreas con mayor rigor climático y subsidiar acciones de planificación ambiental. Los datos del Sistema de Información Hidrológica (HidroWEB), de la Agencia Nacional de Aguas (ANA), permitieron apuntar que: a) los mayores totales pluviométricos se concentran en la parte este de la cuenca, bajo influencia de la altitud del Planalto de Ibiapaba; b) los mayores niveles de ETP se concentran en el sector Centro-Oeste de la cuenca, donde ocurren las temperaturas medias anuales más elevadas; c) los más altos niveles de Ia se concentran también en el sector Centro-Oeste, trecho referente a las áreas aplanadas piauiense que presentan los menores totales de precipitación y los mayores valores de ETP. Estos datos deben subsidiar estudios posteriores y permitir la elaboración e implantación de adecuada planificación ambiental.

Palabras claves: Precipitación; Evapotranspiración Potencial; Rigor Climático; Cuenca de Drenaje.

\section{INTRODUÇÃO}

O Nordeste do Brasil (NEB) constitui uma região em que a ocupação pela colonização europeia iniciou nas margens dos cursos d'água, com posterior expansão para o restante dos terrenos da bacia, a partir de atividades de agricultura (temporárias e permanentes), criação de gado (principalmente, bovino, caprino e ovino) e extração vegetal (produção de carvão e lenha). Essas atividades tem legado à paisagem nordestina grandes alterações nos elementos constituintes de seus sistemas ambientais.

Nessa perspectiva, o conhecimento dos constituintes da paisagem é de fundamental importância para realização de planejamento das atividades humanas. Desse modo, destaca-se que a paisagem do Nordeste do Brasil (NEB) apresenta um relevo com características ruiniformes e/ou em processo de aplainamento, grandes áreas com solos jovens recobertos por uma vegetação adaptada ao regime pluviométrico irregular, a exemplo do bioma caatinga.

Diga-se, ainda, que o NEB é uma região marcada por irregular distribuição espaçotemporal das precipitações, cujos volumes são concentrados em curto período de tempo, além de valores de temperaturas e de totais de evapotranspiração potencial elevados, particularmente em sua parte semiárida. Nesse contexto, insere-se a Bacia Hidrográfica do rio Piracuruca (BHRP), que se localiza entre os estados do Ceará (setor Noroeste) e do Piauí 
(setor Nordeste), particularmente em região semiárida, cujos aspectos climáticos supracitados geram déficit hídrico e, como tal, podem deixar a área com elevado nível de aridez.

Deve-se ressaltar a importância da realização de estudos voltados ao conhecimento do nível de aridez de determinada área, uma vez que isto implica tanto na forma de ocupação humana quanto na estrutura e dinâmica dos ambientes naturais ali encontrados. $O$ índice de aridez pode ser obtido a partir do quociente gerado entre a Precipitação Média (P) e a Evapotranspiração Potencial (ETP). Essa última, de acordo com Ayoade (2001) e Aquino (2010), está associada à perda de água em superfícies com vegetação, ou seja, representa a quantidade de água necessária para a manutenção da vegetação, possibilitando-a manter-se sempre verde em função de determinada temperatura.

Diversos estudos têm sido desenvolvidos utilizando-se do referido índice para mensuração da aridez de diversas áreas no NEB. Dentre esses, destaca-se o de Santos et al. (2010), que elaboraram alguns cenários climáticos futuros para o NEB, mais especificamente para os anos de 2050 e 2100, com base em dados de temperatura do ar médias mensais do período entre 1961 a 2007 e médias climatológicas de precipitação de oitenta e nove localidades no NEB. Os resultados indicaram tendências crescentes nas séries temporais de temperatura do ar, com maior aumento na situação climática atual e para o cenário do ano de 2050, ao passo que o índice de aridez indicou aumento em relação a previsão para o referido ano, principalmente na parte semiárida da região.

Caitano et al. (2011) utilizando Sistemas de Informação Geográfica (SIG) buscaram representar a distribuição espacial da aridez no Ceará, entre os anos de 1976 e 2009. Os resultados indicaram que $75 \%$ da área total desse estado está incluída na isoieta abaixo de 800 mm anuais, cujos valores mínimos e máximos são de $618 \mathrm{~mm}$ e $1.394 \mathrm{~mm}$ anuais, respectivamente. Os totais de ETP médio no estado variaram de $1.243 \mathrm{~mm}$ a $2.212 \mathrm{~mm}$ anuais, cujos maiores totais concentraram-se nas regiões do Sertão dos Inhamuns, do Sertão Central e do Litoral Leste-Jaguaribe. Em relação ao Ia, as áreas semiáridas (Ia entre 0,21 a 0,50) abrangeram $11.386 .517 \mathrm{~km}^{2}$ do estado, equivalendo a 76,16\% de sua área total.

Santiago et al. (2015) caracterizaram a Bacia do rio São Nicolau, no semiárido piauiense, quanto a sua suscetibilidade à desertificação por meio do Ia, utilizando dados pluviométricos de onze postos próximos à bacia, a partir de série histórica de 1963 a 1990. Os dados indicam Ia menor que 0,65 e precipitação variando entre 600 a $870 \mathrm{~mm}$ na maioria dos 
postos, localizados principalmente no alto e médio curso. No baixo curso foram encontrados valores maiores que 0,65 e precipitação entre 900 e 1290 mm, logo há a atuação de um clima do tipo úmido e subúmido. Os resultados apontam para uma uniformidade quanto à suscetibilidade à desertificação na região, com predomínio quase todo o alto curso.

Frente ao exposto, o estudo acerca do Ia torna-se pertinente e oportuno, tendo em vista que a área da BHRP encontra-se localizada em área semiárida. Logo, espacializar os níveis de aridez e conhecer aquelas áreas com maior rigor climático é um dado importante para a ocupação humana e conservação da natureza. Desse modo, a pesquisa se propôs a realizar análise estatística e espacial da Precipitação Média Anual (P), Evapotranspiração Potencial (ETP) e Índice de Aridez (Ia), como forma de conhecer as áreas de maior rigor climático e subsidiar ações de planejamento territorial e gestão ambiental na área da BHRP, elevando a qualidade ambiental e de vida da população.

\section{Localização e caracterização da área em estudo}

A BHRP drena uma área total de $7.625,9 \mathrm{~km}^{2}$. Ela é uma bacia interestadual, situandose no Norte do NEB, entre os estados do Ceará e do Piauí (Figura 1), sendo que a mesma integra a Bacia Hidrográfica do rio Longá (BHRL). O rio Piracuruca nasce na Serra da Ibiapaba, a altura do município de São Benedito, no Ceará, e deságua no rio Longá no município de São José do Divino, já no estado do Piauí.

A área drenada pela BHRP abrange a área de oito municípios cearenses (Viçosa do Ceará, Tianguá, Ubajara, Ibiapina, São Benedito, Carnaubal, Guaraciaba do Norte e Croatá) e dez piauienses (Batalha, São José do Divino, Piracuruca, Cocal, Cocal dos Alves, Brasileira, São João da Fronteira, Piripiri, Pedro II, Domingos Mourão). Contudo, apenas oito sedes municipais situam-se dentro dos limites da BHRP, quais sejam: cinco do lado piauiense (Cocal dos Alves, Domingos Mourão, Piracuruca, São João da Fronteira e São José do Divino) e três pertencentes ao Ceará (Ibiapina, São Benedito e Ubajara). Destaca-se que a soma da população dos oito municípios foi estimada em 154.965 habitantes (IBGE, 2016). 


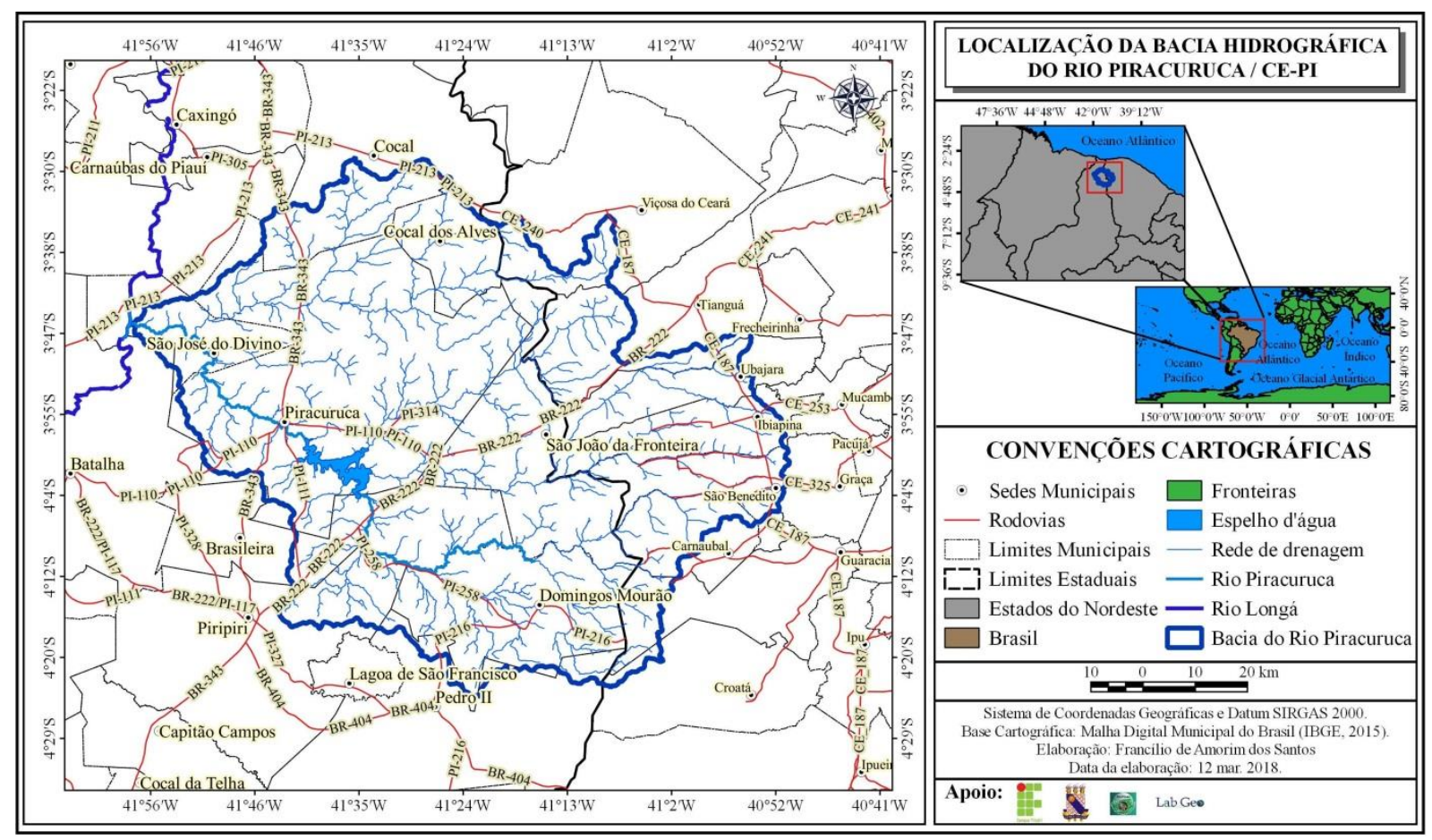

Figura 1 - Localização da Bacia Hidrográfica do rio Piracuruca (BHRP), obtido através da extração automática de bacias usando dados do MDE SRTM (USGS, 2015).

A área em estudo está localizada no contexto geológico da Bacia Sedimentar do Maranhão-Piauí, particularmente limitada a Leste pelo Planalto da Ibiapaba e este, por sua vez, apresenta escarpamento contínuo, abrupto e festonado, com caimento topográfico suave em direção ao estado do Piauí (LIMA, 1982; SOUZA, 2000; SANTOS, 2015b). Desse modo, cabe destacar que a BHRP está assentada sobre as seguintes formações geológicas: Grupo Serra Grande, que data do período Siluriano e ocupa 37\% da área; Pimenteiras, que ocupa $23 \%$ da área estudada e data do período Devoniano Inferior; Cabeça, com datação do período Devoniano Médio, estende-se por 21,8\% da BHRP; Longá, que abrange 0,1\% da bacia e data do Devoniano Superior; Sardinha, que abrange 4,9\% da bacia e data do período Cretáceo; Depósitos Colúvio-Eluviais, cuja datação indica gênese no período Neógeno (CPRM, 2006).

A BHRP apresenta padrão de drenagem dendrítica e suas nascentes situam-se no município cearense de São Benedito, a mais de 890 m no Planalto da Ibiapaba, com exutório no rio Longá a altura do município piauiense de São José do Divino. Diga-se, ainda, que o relevo da BHRP exibe cotas altimétricas que variam de $25 \mathrm{~m}$ a $965 \mathrm{~m}$, com altitude média de 292,5 m. Na parte Oeste dessa bacia ocorrem terrenos com níveis de dissecação forte a 
moderada, notadamente devido à atuação de rios consequentes que seguem as camadas sedimentares inclinadas presentes na região. A jusante das áreas mais dissecadas segue-se extensa área aplainada, na qual se destaca o médio e baixo curso do rio Piracuruca, onde há locais periodicamente inundados nas planícies fluviais ali esculpidas.

Salienta-se que a BHRP apresenta influência da Zona de Convergência Intertropical (ZCIT), com pluviometria concentrada entre janeiro a maio. Destaca-se que área onde se situa a BHRP é afetada pelos efeitos do fenômeno El Niño Oscilação Sul (ENOS) e do Dipolo do Atlântico, que contribuem para gerar anos com anomalias negativas ou positivas. Cabe dizer que o Planalto da Ibiapaba tem grande papel no que diz respeito às precipitações na área estudada, notadamente pela ocorrência de chuvas orográficas no setor Leste da bacia, fato que deixa a vertente a sotavento com totais pluviométricos reduzidos.

Os processos pedológicos atuantes na região resultam em diversas ordens de solos, a saber: Neossolos, predomina em 63\% da bacia; Argissolos, ocorrem em 10,4\%; Latossolos, que se distribuem por 9,4\% da BHRP; Planossolos, encontrados em 7,9\% da área estudada; Plintossolos, ocorrem em 6,0\% da bacia; Vertissolos, Gleissolos e Chernossolos que ocorrem, respectivamente, em 2,1\%, 0,7\% e 0,5\% da bacia estudada (INDE, 2014). Essas ordens de solos associados aos totais pluviométricos, os quais decrescem de Leste para Oeste, são recobertos por distintas fisionomias de vegetação. Desse modo, tem-se o Planalto da Ibiapaba recoberto por mata úmida (ou plúvio-nebular) a barla vento e por mata seca a sotavento, devido à redução das precipitações. Nas áreas rebaixadas pediplanadas estende-se cobertura vegetal do tipo caatinga com distintas fisionomias, variando de porte arbóreo a arbustivo.

\section{METODOLOGIA}

De início, realizou-se levantamento do número de postos pluviométricos a ser utilizados no estudo, junto ao Sistema de Informações Hidrológicas (HidroWEB) da Agência Nacional de Águas (ANA, 2016). Em seguida, foram adquiridos dados de precipitações das séries históricas de 31 anos (1985 a 2015) de 14 (quatorze) postos pluviométricos, sendo 5 (cinco) postos localizados dentro e 9 (nove) fora do limite da bacia (Figura 2). Os dados de precipitação foram empregados na metodologia de Thornthwaite (THORNTHWAITE; MATHER, 1955). Essa metodologia, conforme assevera Nogueira e Lima (1989), possibilita 
contabilizar a água presente no solo, em que a precipitação corresponde ao ganho e a evapotranspiração está relacionada à perda de umidade do solo.

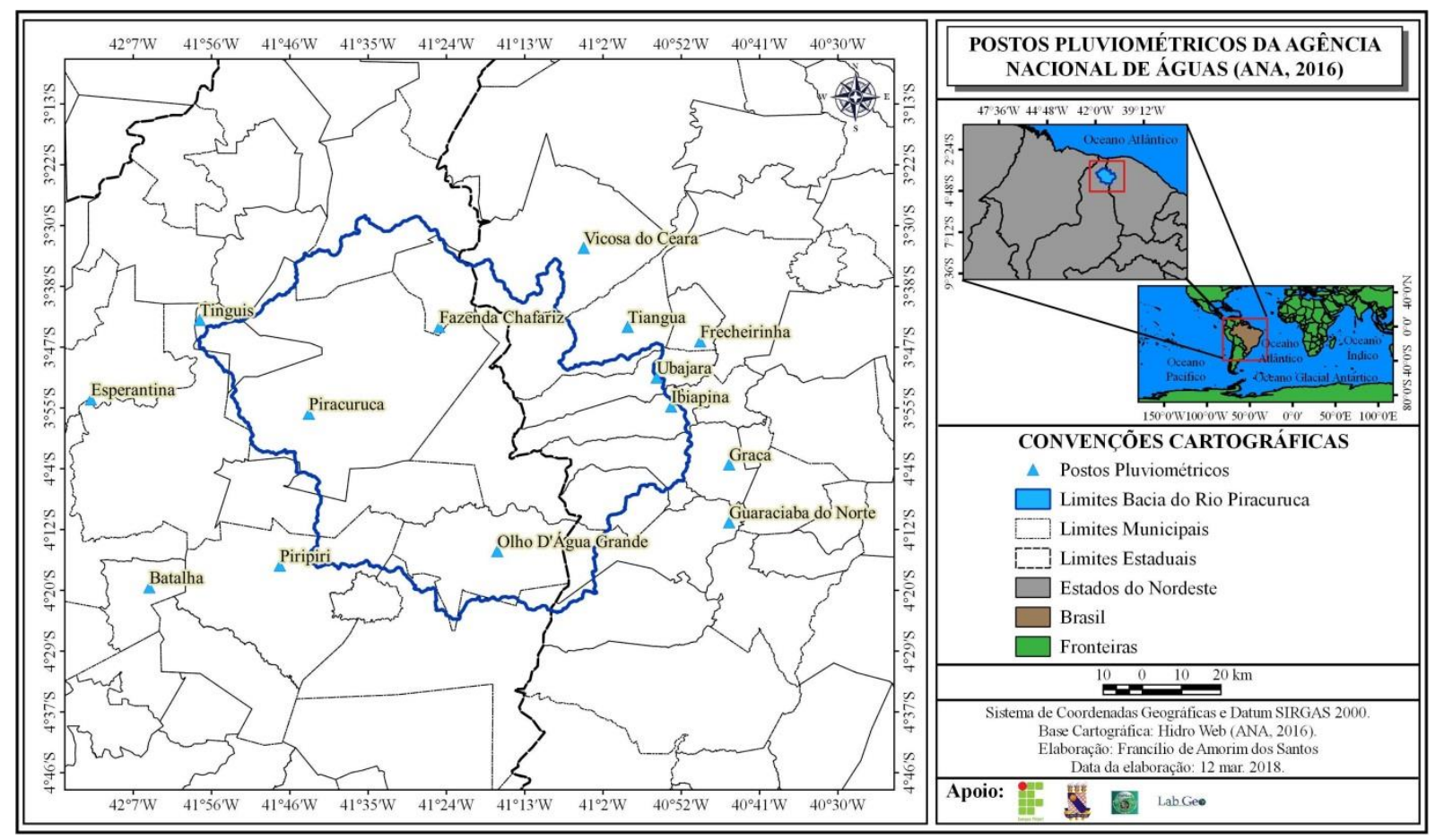

Figura 2 - Localização dos postos pluviométricos gerenciados pela Agência Nacional de Águas (ANA, 2016), utilizados para análise do Índice de aridez (Ia) no interior e no entorno da Bacia Hidrográfica do rio Piracuruca/CE-PI.

Os procedimentos para manuseio e refinamento dos dados dos postos pluviométricos da ANA (2016) foram executados por meio do pacote de programas chamado USUAIS, cuja rotina metodológica está representada nas 4 (quatro) primeiras etapas expostas na Figura 3. Esse conjunto de programas foi elaborado por Oliveira e Sales (2016) e constituem programas escritos e compilados na linguagem Turbo Basic e podem ser utilizados para subsidiar estudos de unidades individuais do ambiente, a exemplo dos dados de postos pluviométricos. 


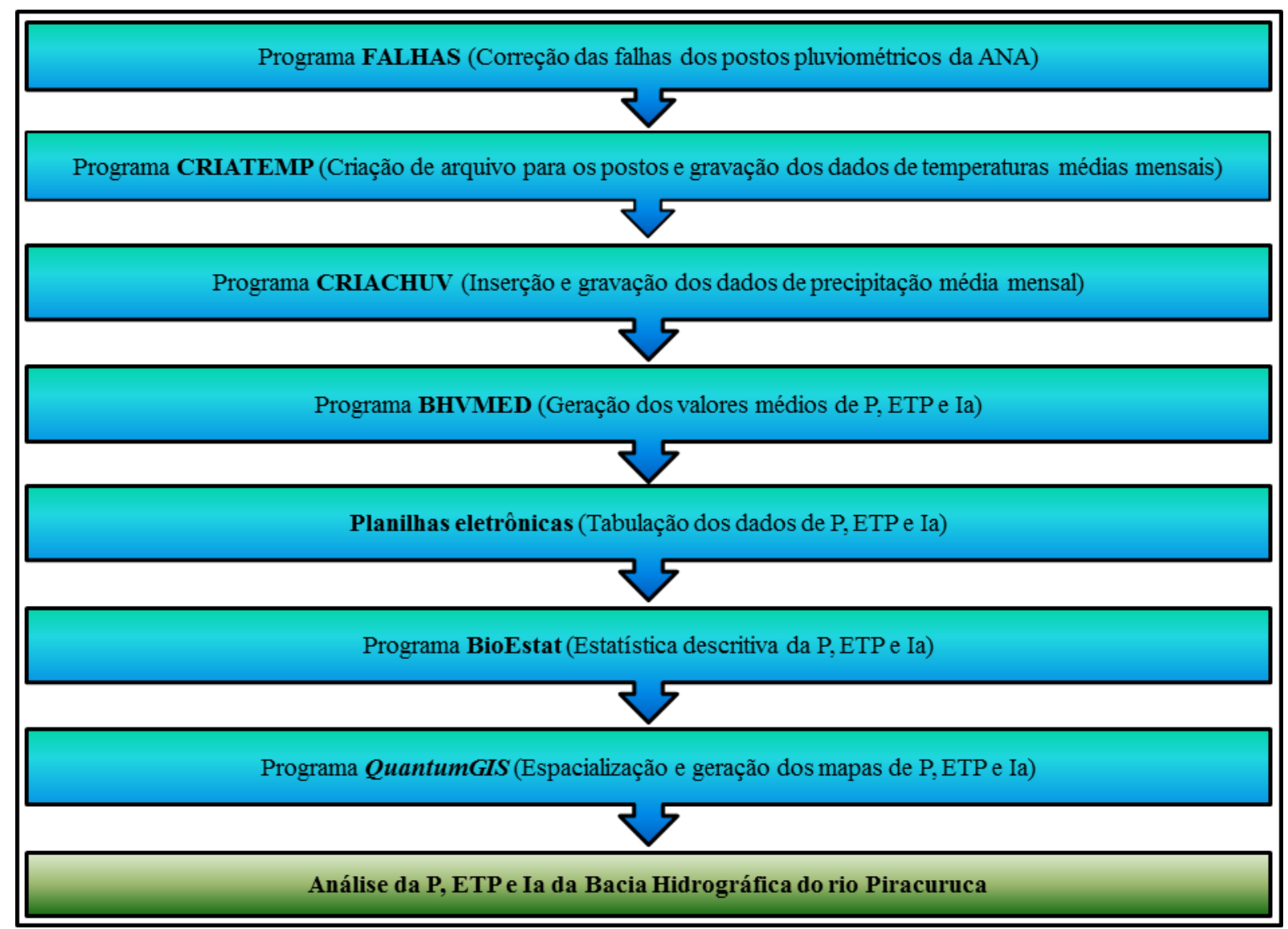

Figura 3 - Rotinas empregadas em distintos programas do pacote USUAIS para refinamento dos dados dos postos pluviométricos da ANA, série histórica de 1985 a 2015.

A priori, realizou-se a correção das falhas nos dados dos postos pluviométricos via rotina realizada na ferramenta FALHAS e uso da técnica de ponderação regional proposto em Tucci (1993). Essa técnica baseia-se no uso de dados de 3 (três) postos referentes à precipitação daquele mês onde ocorreu a falha e a precipitação média na série histórica correspondente ao mês cujo dado se deseja preencher.

O passo seguinte foi realizado através da ferramenta CRIATEMP, que consistiu na criação de um arquivo para cada posto pluviométrico. Em seguida utilizou-se a ferramenta CRIACHUV para inserção e gravação dos dados de precipitação média mensal dos 31 anos da Normal Climatológica. A última etapa realizada foi executada mediante execução de rotina via ferramenta BHVMED, para geração dos valores médios da P, ETP e Ia.

No presente estudo considerou-se $125 \mathrm{~mm}$ como capacidade de armazenamento de água no solo, a exemplo dos estudos de Aquino (2010), Aquino e Oliveira (2013), Santos 
(2015a), Santos e Aquino (2016). Cabe salientar que a ETP foi calculada conforme proposta metodológica de Thornthwaite (1948), sendo que os valores de temperatura média mensal foram obtidos do trabalho de Lima et al. (1982), os quais foram calculados por meio de equações. Ressalta-se que para cada posto pluviométrico foi realizado o cálculo anual do Ia por meio da Equação 1, que considera o quociente entre a Precipitação Média Anual e a Evapotranspiração Potencial Anual.

$I a=\left(\frac{P}{E T P}\right)$

Onde: $\mathrm{Ia}=$ é o Índice de aridez; $\mathrm{P}=$ é a Precipitação Média Anual; ETP = é a Evapotranspiração Potencial Anual.

A delimitação das classes de aridez da BHRP tomou como base as faixas apresentadas em United Nations Environment Programme (UNEP, 1991), cuja metodologia foi inicialmente proposta por Thornthwaite (1941) e aprimorada por Penman (1953). Nesse sentido, buscou-se adaptar essa proposta ao contexto da área em estudo, em que as classes de aridez foram definidas a partir da diferença entre o maior e o menor valor encontrado para os postos pluviométricos pesquisados (Tabela 1), cujo resultado foi dividido por 5 (cinco).

Tabela 1 - Classes e intervalos do Índice de Aridez (IA) estimado para a Bacia Hidrográfica do rio Piracuruca, período de 1985 a 2015.

\begin{tabular}{ll}
\hline Intervalos & Classe atribuída \\
\hline $1,64 \mid--1,90$ & Aridez Muito Baixa \\
$1,38 \mid--1,64$ & Aridez Baixa \\
$1,12 \mid--1,38$ & Aridez Média \\
$0,86 \mid--1,12$ & Aridez Alta \\
$0,60|--| 0,86$ & Aridez Muito Alta \\
\hline
\end{tabular}

Fonte: UNEP (1991). Adaptado pelos autores (2018).

A estatística descritiva foi executada através do software BioEstat, versão 5.0. O mesmo é disponibilizado gratuitamente no site do Instituto Mamirauá. O referido software possibilita aplicar fórmulas e testes estatísticos e gerar tabelas e gráficos para interpretação. 
Nessa pesquisa, consideraram-se alguns parâmetros estatísticos, como máximo, mínimo, mediana, média, desvio padrão, coeficiente de variação $(\mathrm{Cv})$, coeficiente de assimetria (Cas) e coeficiente de curtose $(\mathrm{Ck})$, para cada variável climática estudada.

De posse dos dados, procedeu-se a sua organização em planilhas eletrônicas e em seguida a espacialização por interpolação IDW (peso pelo inverso da distância) das variáveis P, ETP e IA no Sistema de Informação Geográfica (SIG) QuantumGIS (QGIS), versão 2.14 Essen, na tentativa de caracterizar e compreender cada uma das variáveis.

\section{RESULTADOS E DISCUSSÃO}

A seguir serão apresentados e discutidos os produtos obtidos por meio do manuseio e refinamento dos dados de precipitação dos postos pluviométricos da ANA (2016) associados ao uso de programas computacionais. Desse modo, inicialmente será realizada análise estatística e em seguida análise espacial dos referidos dados.

\section{Estatística descritiva}

A priori, cabe dizer que antes de levar os dados - P, ETP e Ia - ao programa BioEstat, foi calculada a média aritmética considerando os dados dos 14 (quatorze) postos utilizados no estudo. Desse modo, por meio da ferramenta "estatísticas circulares" função "estatística descritiva" do referido programa foi possível obter os dados que estão expostos na Tabela 2, que constituem a média dos dados ao longo da série histórica de 31 anos (1985 a 2015).

Tabela 2 - Parâmetros estatísticos básicos da Precipitação (P), Evapotranspiração Potencial (ETP) e Índice de Aridez (Ia) dos postos utilizados para análise da Bacia Hidrográfica do rio

Piracuruca.

\begin{tabular}{lllllllll}
\hline \multirow{2}{*}{ Variável } & \multirow{2}{*}{ Mínimo } & \multirow{2}{*}{ Máximo } & \multirow{2}{*}{ Mediana } & \multirow{2}{*}{ Média } & \multicolumn{2}{l}{$\begin{array}{l}\text { Desvio } \\
\text { Padrão }\end{array}$} & \multicolumn{2}{l}{ Coeficientes } \\
\cline { 7 - 9 } & & & & & & Cv & Cs & Ck \\
\hline P & 865,7 & 1710,9 & 1403,3 & 1346,4 & 230,6 & $17,13 \%$ & $-0,72$ & 0,27 \\
Ia & 902,0 & 1643,0 & 1488,0 & 1363,1 & 300,2 & $22,03 \%$ & $-0,72$ & $-1,29$ \\
\hline
\end{tabular}

Legenda: $\mathrm{Cv}=$ Coeficiente de variação; $\mathrm{Cs}=$ coeficiente de simetria; $\mathrm{Ck}=$ Coeficiente de curtose.

Fonte: Elaborado pelos autores (2018). 
A precipitação pluviométrica na BHRP variou de 865,7 a $1710,9 \mathrm{~mm}$ anuais, portanto infere-se que a bacia em estudo apresenta pelo menos tipos climáticos que variam do semiárido ao subúmido. Ressalta-se que esses valores extremos de precipitação são suficientes para possibilitar a ocorrência de eventos de secas ou inundações. $\mathrm{O}$ valor da média foi inferior ao da mediana, logo apresentou distribuição assimétrica negativa, com grande parte dos dados acima da média. Quanto ao desvio-padrão, pode-se notar alta dispersão em relação à média, visto que os dados apresentaram desvio de 230,6 mm para mais ou para menos, fato ocorrido em função de ter-se trabalhado com dados de postos diferentes e situados em diferentes fisiografias (por exemplo, posto situado no Planalto da Ibiapaba).

Por sua vez, o Coeficiente de variação (Cv) apresentou variações inferiores a 17,13\%, devido a irregular distribuição espaço-temporal das precipitações no NEB, que na BHRP está associada a sua fisiografia, ou seja, influência do Planalto da Ibiapaba, que causa chuvas orográficas na parte mais alta da bacia. Por outro lado, as áreas rebaixadas e situadas mais para o interior, longe do mar, exibem menor quantidade de chuvas. Os dados de precipitação apresentaram distribuição assimétrica negativa, quando analisado o Coeficiente de assimetria (Cas). Por sua vez, o Coeficiente de curtose (Ck) apresentou distribuição de frequência mais achatada que a distribuição normal com a curva mais aberta, ou seja, platicúrtica, que se pode associar a irregularidade na distribuição pluviométrica na área estudada.

Foram encontrados valores de ETP para a BHRP que variaram de 902,0 a 1643,0 mm anuais, que resultam das altas temperaturas anuais do NEB. Esses valores elevados geram significativas perdas de umidade para a atmosfera e, por conseguinte, podendo resultar em déficit hídrico no âmbito da bacia estudada. A ETP, também, apresentou o valor da mediana superior à da média, portanto, uma distribuição assimétrica negativa. Com o desvio-padrão de 300,2 mm, infere-se que ocorra alta dispersão em relação à média. Quanto ao Coeficiente de variação $(\mathrm{Cv})$, o mesmo ficou com 22,03\%, considerado moderado. O Coeficiente de assimetria (Cas) apresentou distribuição assimétrica negativa, pois o valor da média foi inferior ao da mediana. Por sua vez, o Coeficiente de curtose $(\mathrm{Ck})$ possui distribuição de frequência com curva aberta, denominada leptocúrtica, que sugere relativa regularidade espaço-temporal da ETP. Cabe dizer que o valor do $\mathrm{Ck}$ pode ser resultado do balanceamento entre os dados dos postos utilizados, ou seja, os postos da Ibiapaba com valores mais baixos em detrimento dos postos das áreas rebaixadas que exibiram volume de ETP mais alto. 
O parâmetro climático Índice de aridez (Ia) apresentou variação de 0,60 a 1,90, característico de climas semiárido a subúmido úmido e, como tal, constitui elemento indicativo que esta é uma área com predisposição à ocorrência de secas. O Ia apresentou valor da mediana inferior ao da média, logo distribuição assimétrica positiva, com grande parte dos dados abaixo da média. O desvio-padrão possui baixa dispersão em relação à média, com valor de 0,40 . O Coeficiente de variação $(\mathrm{Cv})$ indicou variação de $37,47 \%$, considerado alto e que pode ser explicado pelos diferentes tipos climáticos que ocorrem na BHRP, notadamente pelas distintas fisionomias encontradas na BHRP, ou seja, os terrenos do alto vale do rio Piracuruca possuem cotas altimétricas mais elevadas, situado no Planalto da Ibiapaba, e o baixo vale em áreas aplainadas. O Ia possui distribuição assimétrica positiva no que tange ao Coeficiente de assimetria (Cas), posto que o valor da média tenha sido superior ao da mediana. O Coeficiente de curtose (Ck), por sua vez, apresentou distribuição de frequência platicúrtica, que pode ser associado ao fato que a área da bacia situada na parte superior e reverso imediato do Planalto da Ibiapaba apresenta Ia menos rigoroso, enquanto as áreas aplainadas em direção ao Piauí exibem maior aridez.

\section{Análise espacial}

Os dados de precipitação dos postos da ANA (2016) foram organizados em planilhas eletrônicas e espacializados no SIG QGIS. Ressalta-se que a BHRP, que está sobre influência da ZCIT, apresenta totais pluviométricos anuais que variam de 860 a 1710 mm anuais (Figura 4). Desse modo, pode-se visualizar que o maior valor de precipitação localiza-se na parte Leste da bacia, devido a maior altimetria dos terrenos ali localizados, como tal, a influência do fator orográfico oriundo do Planalto da Ibiapaba. Por outro lado, o distanciamento em direção às áreas aplainadas no sentido Oeste leva a ocorrência de totais pluviométricos típicos de clima semiárido a subúmido seco. 


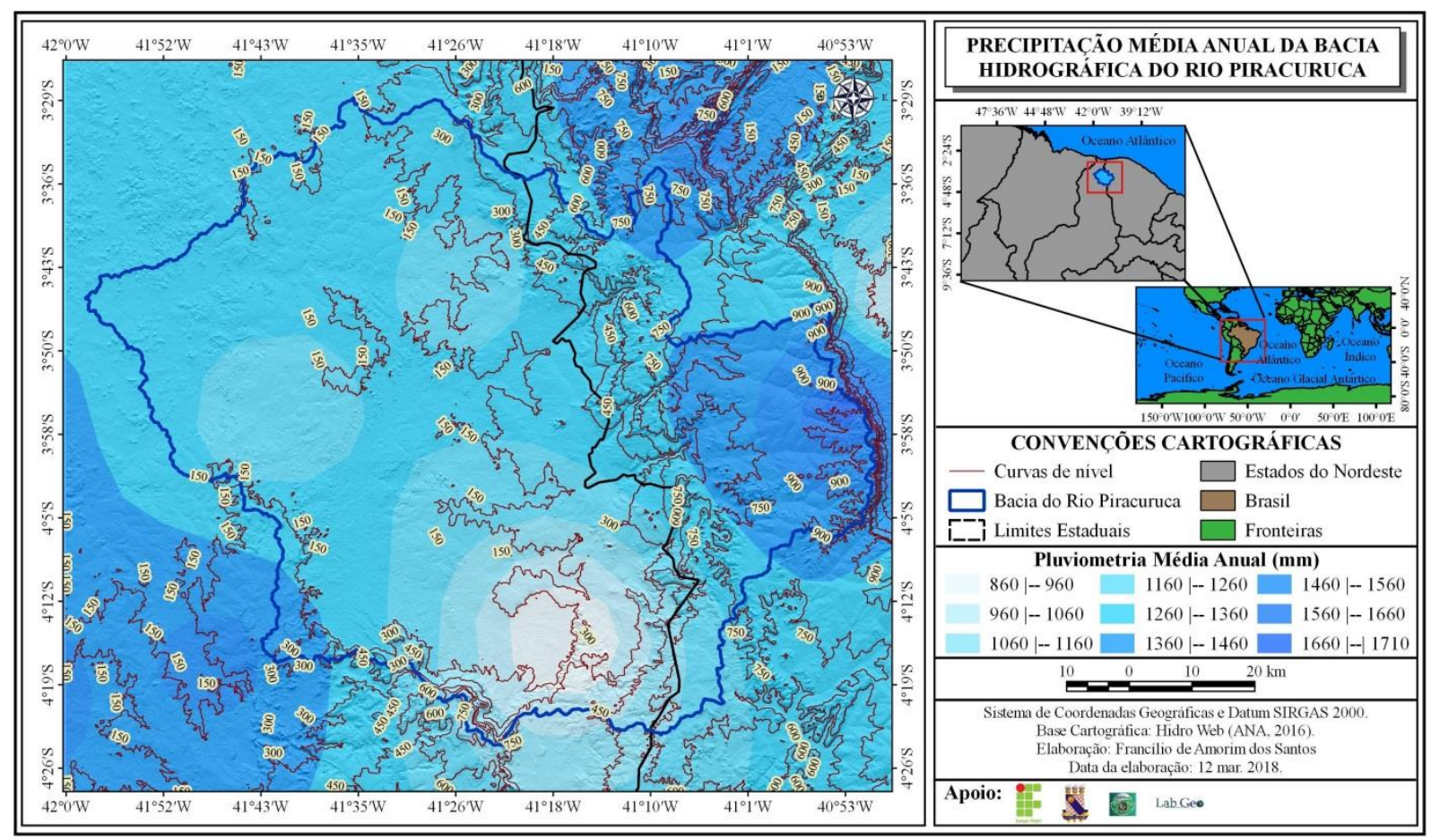

Figura 4 - Precipitação Média Anual (P) da Bacia Hidrográfica do rio Piracuruca (BHRP), obtido por meio da espacialização dos dados dos postos pluviométricos da ANA (2016) no SIG QGIS.

Destaca-se que anualmente ocorre distribuição irregular das chuvas, particularmente devido à atuação conjunta da ZCIT e os fenômenos El Niño Oscilação Sul (ENOS) e as fases positiva ou negativa do Dipolo do Atlântico, que resultam em anos normais, secos ou chuvosos. Nesse sentido, por meio da Figura 5 pode-se observar que há concentração das chuvas de janeiro a maio, com maior pluviometria ocorrendo no mês de março com 331,8 $\mathrm{mm}$, seguido pelo mês de abril que apresenta $287,6 \mathrm{~mm}$. Não por acaso esses são os meses em que a ZCIT atinge sua posição mais meridional e, por conseguinte, prova maior volume de chuvas no setor Norte do Nordeste do Brasil. Por outro lado, entre os meses de junho a dezembro, notadamente agosto e setembro, período em que a ZCIT encontra-se na sua posição mais setentrional, ocorre uma considerável redução das precipitações, período esse considerado seco e, como tal, apresenta maiores níveis de evapotranspiração e aridez. 


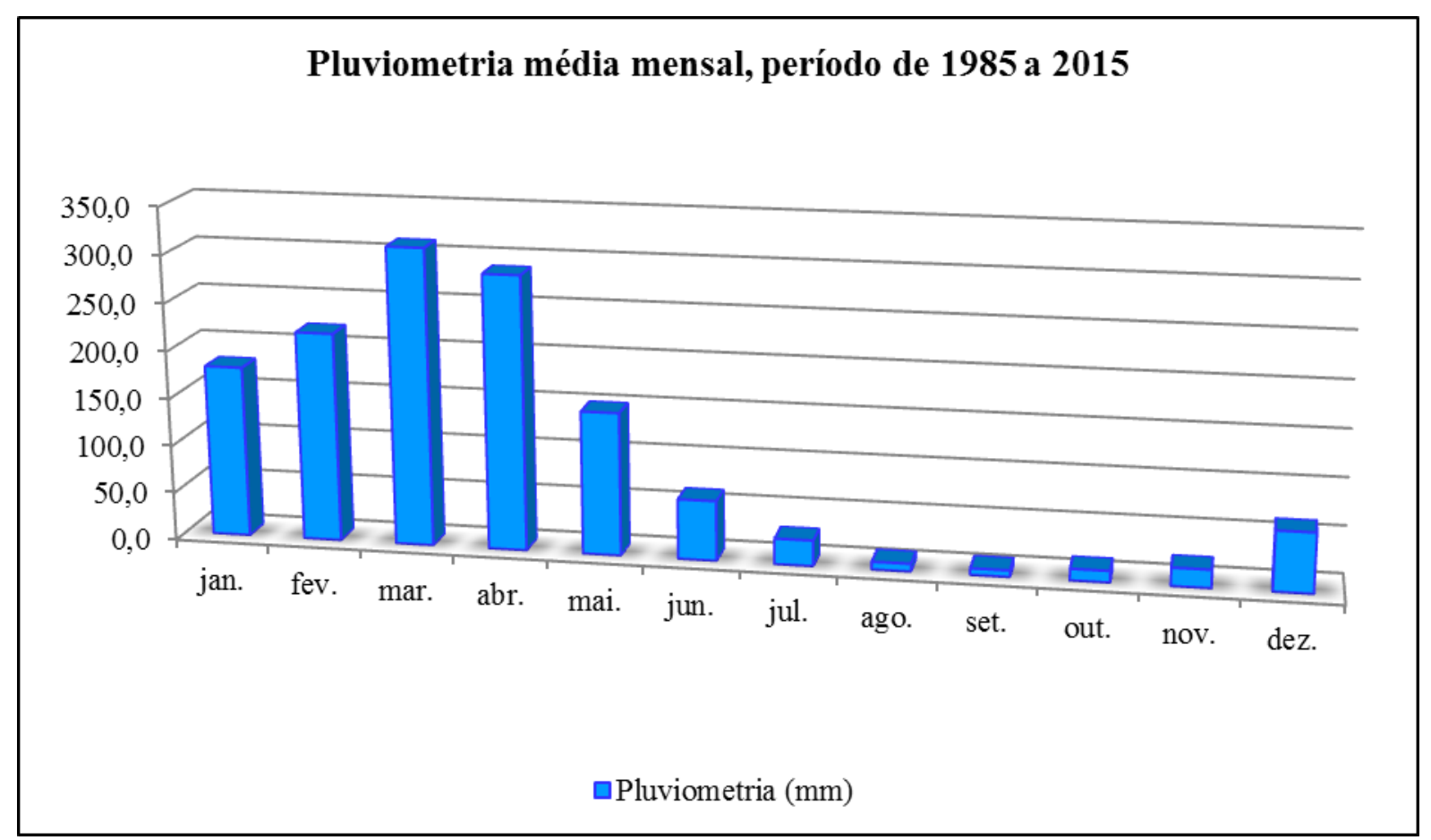

Figura 5 - Precipitação média mensal dos postos utilizados no estudo, período de 1985 a 2015.

Fonte: ANA (2016).

Os dados aqui encontrados são corroborados pelo estudo de Caetano et al. (2011). Esses pesquisadores afirmam que uma das regiões cearenses com maiores médias anuais de precipitação se concentra no setor Noroeste (região da Serra da Ibiapaba). Admitem, ainda, que a distribuição das chuvas no referido setor sofre uma forte influência do efeito orográfico.

Por sua vez, os totais de Evapotranspiração Potencial (ETP) variaram de 903 a 1643 mm anuais. A Figura 6 possibilita afirmar que os maiores níveis de ETP da bacia concentramse no setor Centro-Oeste. Fato esse que pode ser aliado as mais elevadas médias de temperatura anual, conforme aponta o estudo de Santos e Cruz (2016), que indicou predomínio de temperaturas que variam de $24^{\circ} \mathrm{C}$ a $26^{\circ} \mathrm{C}$ em $54,6 \%$ da área da BHRP. Tal fato confirma a influência da altitude e da distância em relação ao Planalto da Ibiapaba, ou seja, à medida que se afasta em direção Oeste maior será o rigor climático. 


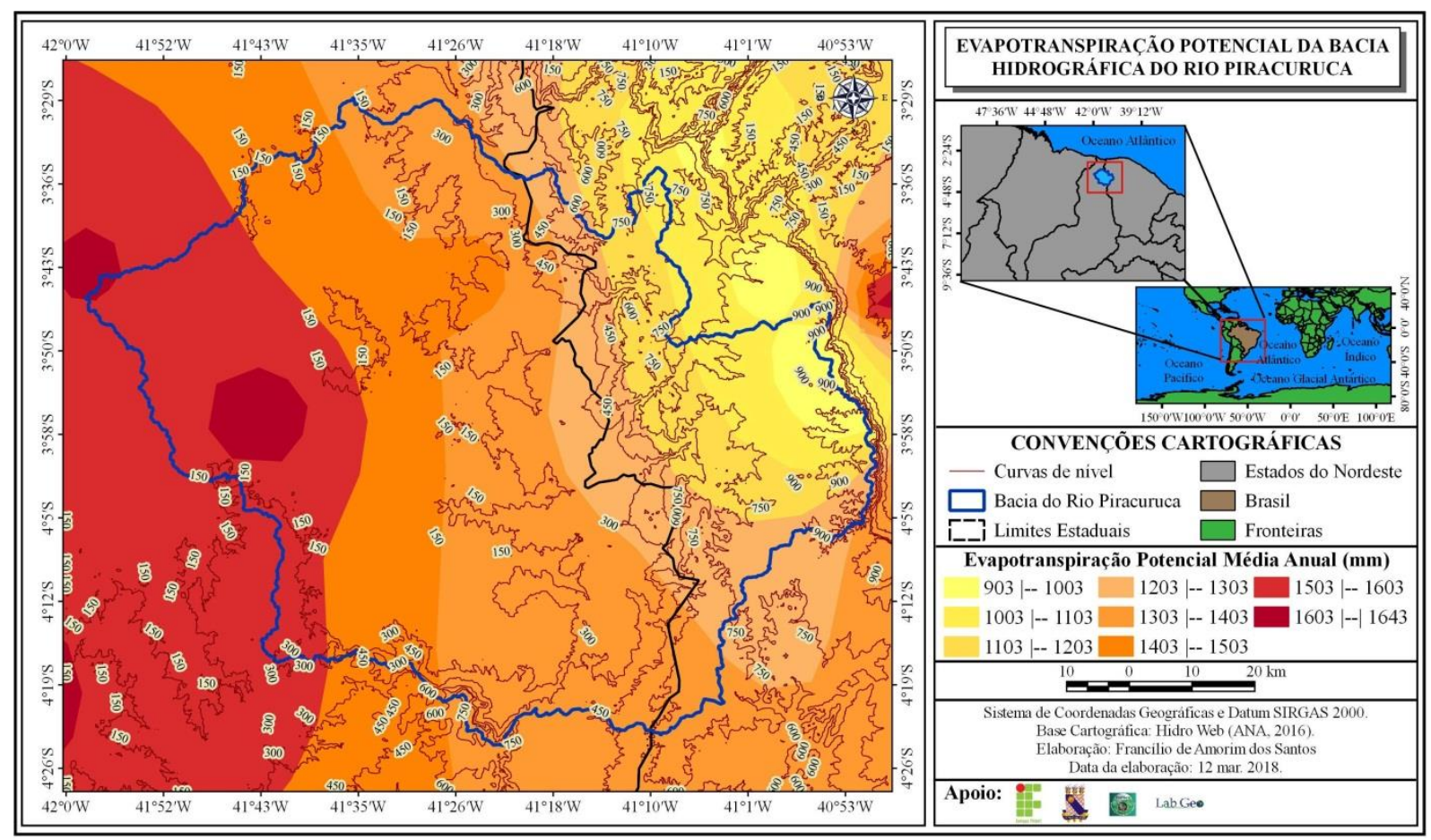

Figura 6 - Evapotranspiração Potencial Média Anual (ETP) da Bacia Hidrográfica do rio Piracuruca (BHRP), estimada por meio do pacote de programas USUAIS e espacializado no SIG QGIS.

Sobre a ETP, Santos et al. (2010) apontam mudanças no cenário nordestino para 2050 e 2100. Os seus resultados apontam tendência ao aumento dos totais de EPT na área onde está inserida a BHRP, com redução da área mesotérmica $(997 \mathrm{~mm}<$ ETP $>1.140 \mathrm{~mm}$ ) para o cenário de 2050, enquanto o cenário para 2100 aponta que praticamente todo o Nordeste se tornará uma área megatérmica $(E T P>1.140 \mathrm{~mm})$.

A área considerada de mais alto Índice de aridez (Ia) concentra-se no setor CentroOeste da BHRP (Figura 7), notadamente a partir dos limites entre os estados do Ceará e do Piauí, posto que seja o setor com maiores níveis de ETP e menor volume de precipitação. Entretanto, nota-se que a maior parte da área da BHRP apresenta Ia moderado a muito alto, enquanto níveis de Ia baixo são encontrados no Planalto da Ibiapaba, particularmente devido ser a área que apresenta maior volume pluviométrico e os menores valores de ETP. 


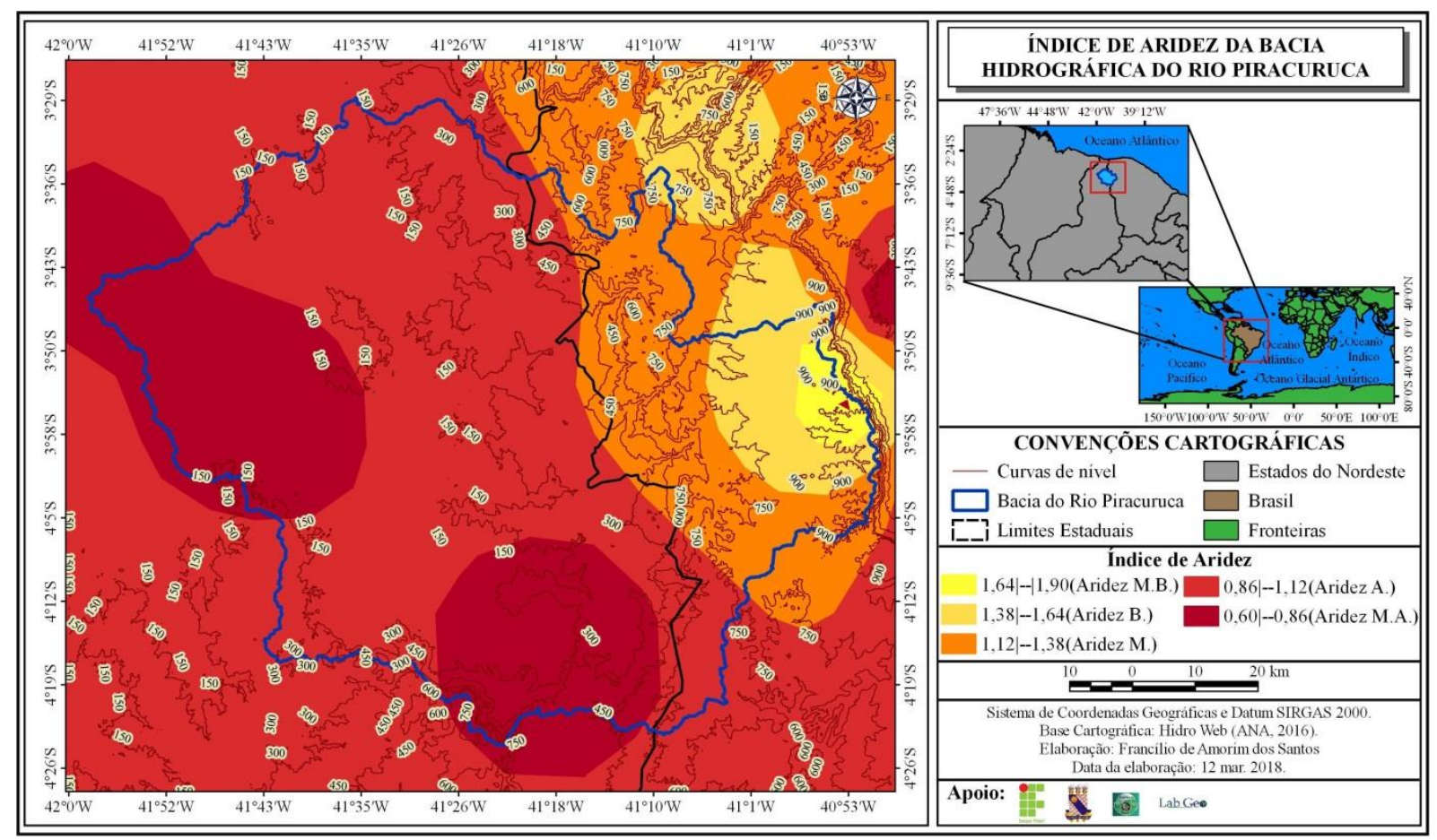

Figura 7 - Índice de aridez (Ia) da Bacia Hidrográfica do rio Piracuruca (BHRP), estimado por meio do pacote de programas USUAIS e espacializado no SIG QGIS.

Os dados de Ia do presente estudo assemelham-se aos de Santiago et al. (2015), cujo estudo apontou que as áreas de maior aridez na Bacia do rio São Nicolau (PI) foram identificados nos setores com menores totais de precipitação, enquanto que aquelas áreas classificadas como sendo do tipo climático úmido e subúmido apresentam maiores volumes de precipitação e, por conseguinte, menor aridez.

\section{CONCLUSÕES}

O presente estudo corrobora a variabilidade espaço-temporal das características climáticas do Nordeste do Brasil (NEB), em específico da Precipitação Média Anual (P), Evapotranspiração Potencial (ETP) e Índice de Aridez (Ia), quando considerada a série histórica de 31 anos (1985 a 2015). Ao passo que a estatística descritiva constituiu-se importante ferramenta na estimativa das variáveis climáticas da bacia, uma vez que certificou a variação dos dados em relação à média histórica. 
Quando espacializados, os dados de precipitação pluviométrica apontaram que os maiores totais pluviométricos se concentram na parte leste, que sofre influência dos fatores altitude e forma da Serra da Ibiapaba. Por outro lado, a parte Sudeste a Sul destaca-se por apresentar pluviometria típica do semiárido. No que tange aos níveis de Evapotranspiração Potencial, estes se concentram no setor Centro-Oeste, o que pode ser associado as mais elevadas médias de temperatura anual nesse setor. A área com o mais alto Ia concentra-se no setor Centro-Oeste da BHRP, área aplainada em direção ao estado do Piauí, onde ocorrem os menores totais de precipitação e os mais elevados volumes de ETP.

As informações aqui apresentadas e analisadas não esgotam as possibilidades de estudos acerca das condicionantes climáticas que atuam na área da Bacia Hidrográfica do rio Piracuruca, mas tornam-se ponto de partida para estudos posteriores. As pesquisas futuras devem buscar associar o estudo de outros componentes ambientais, ou seja, propor-se a realizar uma análise integrada da paisagem da BHRP. Nesse sentido, ao conhecer-se a dinâmica ambiental da referida bacia será possível elaborar e implementar adequado planejamento ambiental e territorial para convivência com sua diversidade.

\section{REFERÊNCIAS}

ANA - Agência Nacional de Águas. Hidro Web - Sistema de Informações Hidrológicas. Séries históricas - ano de 1985 a 2015. Disponível em 〈http://hidroweb.ana.gov.br/>. Acesso em: 25 jun. 2016.

AQUINO, C.M.S. Estudo da degradação / desertificação no núcleo de São Raimundo

Nonato - Piauí. Tese (Doutorado em Geografia). Universidade Federal de Sergipe - UFSE. São Cristovão, 2010.

AQUINO, C.M.S.; OLIVEIRA, J.G.B. Emprego do Método de Thornthwaite \& Mather (1955) para Cálculo do Balanço Hídrico Climatológico do Núcleo de Degradação de São Raimundo Nonato-Piauí. Revista Brasileira de Geografia Física, v. 06, n. 01, p.79-90, 2013. AYOADE, L.O. Introdução à climatologia para os trópicos. Tradução de Maria Juraci Zani dos Santos; revisão de Suely Bastos; coordenação editorial de Antonio Christofoletti. - $6^{\mathrm{a}}$ ed. - Rio de Janeiro: Bertrand Brasil, 2001.

BRASIL. Lei Federal $\mathbf{n}^{\mathbf{0}}$ 9.433, de 08 de janeiro de 1997. Institui a Política Nacional de Recursos Hídricos, cria o Sistema Nacional de Gerenciamento de Recursos Hídricos, regulamenta o inciso XIX do art. 21 da Constituição Federal, e altera o art. $1^{\circ}$ da Lei $n^{\circ} 8.001$, de 13 de março de 1990, que modificou a Lei n 7.990, de 28 de dez.de1989.

CAITANO, R.F.; LOPES, F.B.; TEIXEIRA, A.S. Estimativa da aridez no Estado do Ceará usando Sistemas de Informação Geográfica. In: Simpósio Brasileiro de Sensoriamento Remoto, XV, Curitiba - PR. Anais... Curitiba: 2011, p.8.904-8.911. 
CPRM - Serviço Geológico do Brasil. Ministério de Minas e Energia. Mapa Geológico do Estado do Piauí. $2^{\text {a }}$ Versão. Teresina, 2006.

IBGE - Instituto Brasileiro de Geografia e Estatística. Cidades. Disponível em <www.cidades.ibge.gov.br>. Acesso em: 10 set. 2016.

Malha municipal digital do Brasil: situação em 2014. Rio de Janeiro: IBGE, 2014. Disponível em: <ftp://geoftp.ibge.gov.br/malhas_digitais/>. Acesso em: 04 abr. 2016.

LIMA, I.M.M.F. Caracterização Geomorfológica da Bacia Hidrográfica do Rio Poti. Rio de Janeiro. 1982. Dissertação (Mestrado em Geografia) - Programa de Pós-Graduação em Geografia, Instituto de Geociências - Universidade Federal do Rio de Janeiro. 1982.

LIMA, M.G.; ALENCAR, P.A.M.; COELHO, H. Normais de temperatura máxima, mínima e média estimadas em função da latitude, longitude e altitude para o estado do Piauí. Ensaios Boletim de Pesquisa, v. 1, n 1, p.1-40, 1982.

OLIVEIRA, J.G.B.; SALES, M.C.L. Usuais: programas para uso em análise ambiental. Revista Equador (UFPI), Vol. 5, n. 2, p.36-60, Janeiro/Junho, 2016.

PENMAN, H.L. The Physical Bases of Irrigation Control, in Report 13th Int. Hort. Congr., 2, 11 pages, Royal Horticultural Society, London, 1953.

NOGUEIRA, F.C.B.; LIMA, F.A.M. Classificação climática de Thornthwaite dos municípios de Pacoti e Guaramiranga, Ceará. Revista Ciência Agronômica, Fortaleza, v.20, n.1/2, jun./dez., p.175-183, 1989.

SANTIAGO, C.M.C.; SALES, M.C.L.; PAULA, J.E.A. Índice de Aridez na Bacia do rio São Nicolau (semiárido piauiense) e a suscetibilidade à desertificação. In: Workshop Internacional sobre Água no Semiárido Brasileiro, II, Campina Grande - PB. Anais... Campina Grande: 2015, p.1-6.

SANTOS, D.N.; SILVA, V.P.R.; SOUSA, F.A.S.; SILVA, R.A. Estudo de alguns cenários climáticos para o Nordeste do Brasil. Revista Brasileira de Engenharia Agrícola e Ambiental, v.14, n.5, p.492-500, 2010.

SANTOS, F.A. Mapeamento das unidades geoambientais e estudo do risco de degradação/desertificação nos municípios de Castelo do Piauí e Juazeiro do Piauí. Dissertação (Mestrado em Geografia) - Programa de Pós-Graduação em Geografia (PPGGEO) / Universidade Federal do Piauí. 2015a.

SANTOS, F.A.; AQUINO, C.M.S. Balanço hídrico climatológico dos municípios de Castelo do Piauí e Juazeiro do Piauí, Nordeste, Brasil. Revista Eletrônica Geoaraguaia. Barra do Garças-MT. V 6, n.1, p.30 a 56. Janeiro/julho. 2016.

SANTOS, F.A.; CRUZ, M.L.B. Balanço hídrico climatológico da bacia hidrográfica do rio Piracuruca, Nordeste do Brasil. In: Congresso Internacional da Diversidade do Semiárido CONIDIS, I, Campina Grande - PB. Anais... Campina Grande: 2016, p.1-12.

SANTOS, F.L.A. Bases Geográficas ao Zoneamento Ecológico-Econômico do Planalto da Ibiapaba: Municípios de Tianguá e Ubajara - Noroeste do Ceará. Dissertação (Mestrado em Geografia) - Programa de Pós-Graduação em Geografia, Centro de Ciências e TecnologiaUniversidade Estadual do Ceará. 2015b.

SOUZA, M.J.N. Bases Naturais e Esboço do Zoneamento Geoambiental do Estado do Ceará. In: LIMA, L.C.; SOUZA, M. J. N.; MORAES, J. O. Compartimentação territorial e gestão regional do Ceará. Fortaleza: FUNECE. 2000. p.13-98.

THORNTHWAITE, C.W. An approach toward a rational Classification of Climate, The Geographical Review. New York, v.XXXVIII, p.55-94, 1948.

Atlas of Climatic Types in the United States. Miscell Publ, n.421. U.S.

Department of Agriculture, Forest Service, 1941. 
THORNTHWAITE, C.W.; MATHER, J.R. The Water Balance - Publications in Climatology. New Jersey: Centerton, v. VIII, $n^{\circ}$ 1, 1955.

TUCCI, C.E.M. Hidrologia: ciência e aplicação. Porto Alegre: Eds. da UFRGS e da USP, 1993.

UNEP - United Nations Environment Programme. Status of desertification and implementation of the United Nations Plan of Action to Combat Desertification. Nairóbi, 1991.

USGS - United States Geological Service (Serviço Geológico dos Estados Unidos). Earth Explorer - Digital Elevation - SRTM 1 Arc-Second Global. 2015. Disponível em <http://earthexplorer.usgs.gov/>. Acesso em: 23 nov. 2015.

Recebido em 05 de março de 2018.

Aceito em 20 de março de 2018. 